http://jmscr.igmpublication.org/home/

ISSN (e)-2347-176x ISSN (p) 2455-0450

crossref DOI: https://dx.doi.org/10.18535/jmscr/v7i8.166

Journal Of Medical Science And Clinical Research

\title{
A Case of Cerebral Venous Sinus Thrombosis in a Patient with Sickle Cell Disease
}

\author{
Authors \\ Dr M Mallikarjuna Reddy ${ }^{1}$, Dr B Vinu ${ }^{2}$, Dr Rajasekaran Durai ${ }^{3}$ \\ ${ }^{1}$ Postgraduate, Department of General Medicine, Chettinad Hospital \& Research Institute, Chettinad \\ Academy of Research and Education \\ ${ }^{2}$ Assistant Professor, Department of General Medicine, Chettinad, Hospital \& Research Institute, Chettinad \\ Academy of Research and Education \\ ${ }^{3}$ Professor, Department of General Medicine, Chettinad Hospital \& Research Institute, Chettinad Academy \\ of Research and Education
}

\begin{abstract}
We report a 30 year old woman with sickle cell disease (SCD) who presented with a severe right side headache and neck pain of 1 week duration. Results of a peripheral smear showed sickle cells and sickling test was positive. Magnetic resonance venography showed dural venous sinus thrombosis involving right transverse and sigmoid sinuses with venous infarcts involving right temporal \& occipital lobes. The patient was treated with low molecular weight heparin, mannitol and her symptoms and signs resolved.

Keywords: Sickle cell disease, Dural venous sinus thrombosis, Magnetic resonance venography, Low molecular weight heparin.

Key Message: Involvement of Transverse sinus and Sigmoid sinus without involvement of Sagittal sinus is rare.
\end{abstract}

\section{Introduction}

Sickle cell disease (SCD) is a well-known hereditary hematologic disorder of hemoglobin. SCD has been reported as a cause of dural venous sinus thrombosis (DVST) events. The involvement of transverse and sigmoid sinus without involvement of sagittal sinus is rare.

\section{Case Report}

A 30 year old woman was admitted with severe right side headache and neck pain of 1 week duration. The character of the pain does not suggest migraine or raised Intracranial tension though the patient gave history of migraine in the past. Patient is a known case of sickle cell disease with two other family members were affected, one of the younger brother died of sickle cell crisis. Patient is recently married and not on any contraceptive. On examination patient was conscious and oriented. She was pale with periorbital puffiness (Right>Left) with stable vitals. Her neurological examination, cardiovascular examination and respiratory examination did not reveal any abnormality.

Her haematological investigation revealed a haemoglobin of $10.1 \mathrm{~g} / \mathrm{dl}$ with hematocrit of $30.5 \%$, reticulocyte count $0.5 \%$ and marked neutrophilic leukocytosis. Peripheral smear showed sickle cells and target cells (figure $1 \& 2$ ), sickling test was positive. Her urine examination, 


\section{JMSCR Vol||07||Issue||08||Page 970-972||August}

renal function tests, liver function tests were within normal limits. Serology for retrovirus, hepatitis and ANA were negative. Her workup for procoagulant state indicated negative for Antiphospholipid antibodies, antithrombin-3, factor $\mathrm{V}$ leiden mutation and Protein $\mathrm{C}$ levels. The only abnormality was reduced protein $\mathrm{S}$ levels which were low.

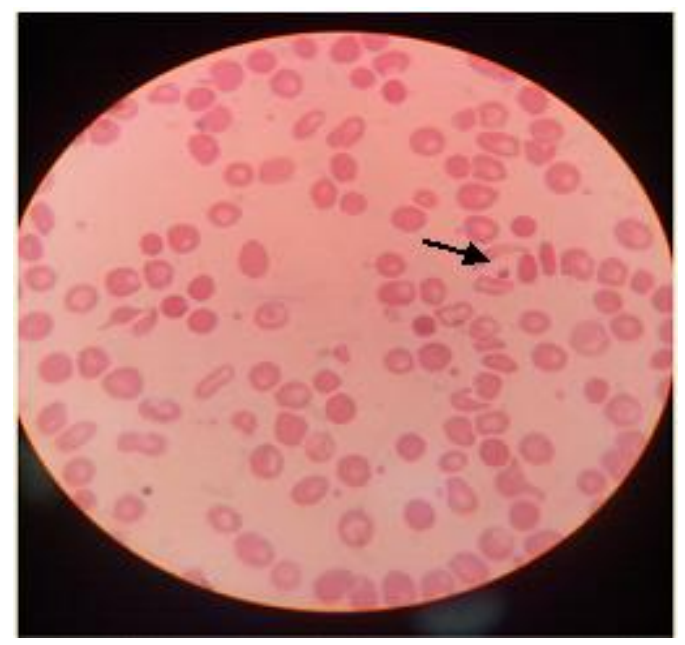

Figure 1

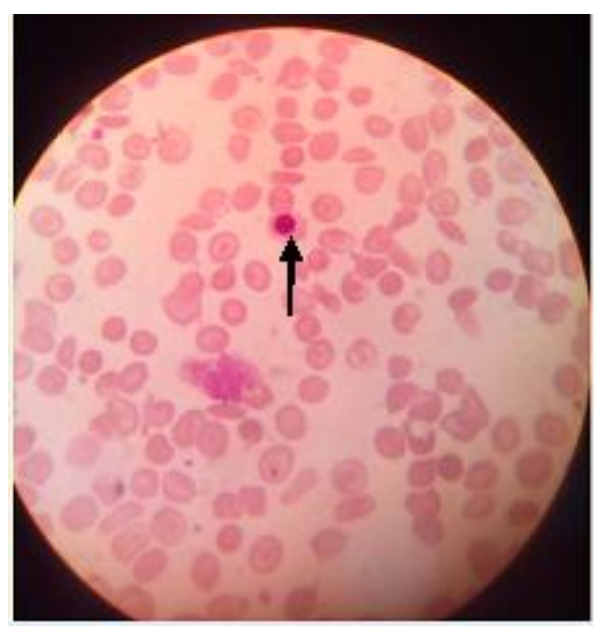

Figure 2

MRI, MRV of the patient showed dural venous sinus thrombosis involving right transverse and sigmoid sinuses (figure 3,4,5) with venous infarcts involving right temporal \& occipital lobes. A diagnosis of Aseptic dural venous sinus thrombosis due to sickle cell disease was made, possibly due to protein $\mathrm{S}$ deficiency and patient was started on low molecular weight heparin and patient improved.

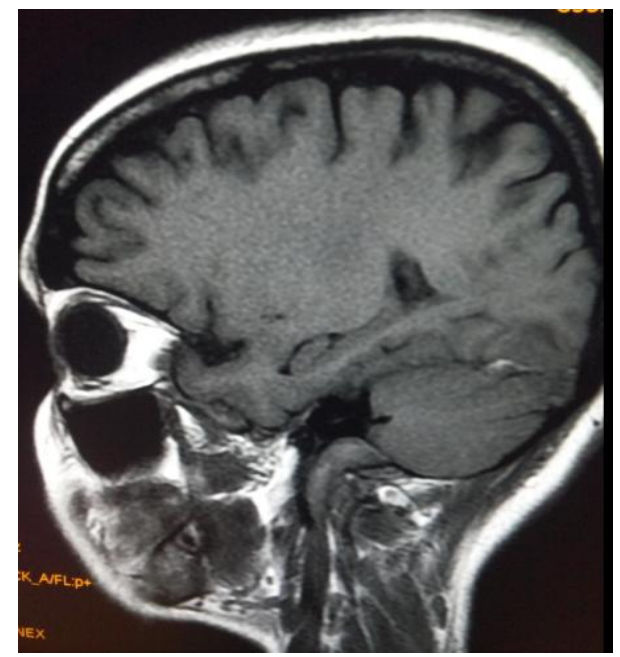

Figure 3

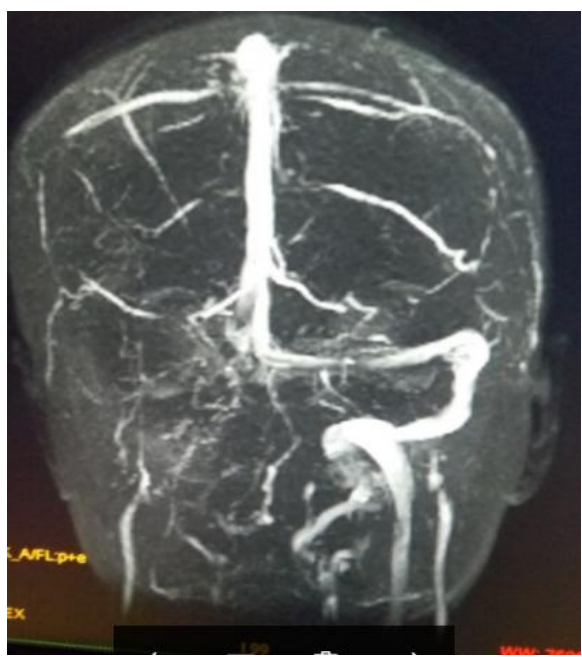

Figure 4

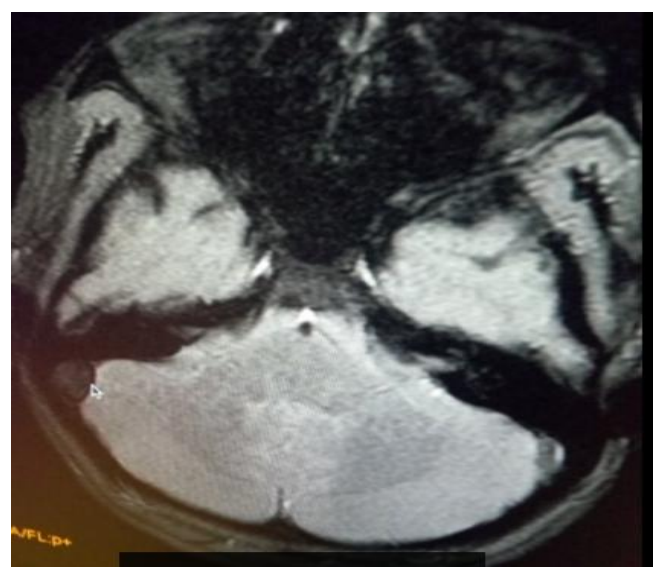

Figure 5

\section{Discussion}

Dural venous sinus thrombosis can affect any of the superficial or deep cerebral veins, but most commonly involved one is the sagittal sinus. In our patient right transverse sinus and sigmoid sinus were involved without involvement of 
sagittal sinus. Clinical manifestations are nonspecific, they can vary from isolated headache to coma. It may be associated with trauma, infections, renal failure and hematological disorders. In SCD there is an increased adherence of sickle cells to the vascular endothelia. Abnormal platelet activation, endothelial cell damage and activation of cell adhesion molecules, low levels of proteins $\mathrm{C}$ and $\mathrm{S}$, and increased antiphospholipids contributes furthur to thrombogenesis and vascular occlusion in SCD.

In our patient hypercoagulation profile were negative, except for the low levels of protein $\mathrm{S}$. Diagnosis is confirmed by detection of the thrombus in the cerebral venous sinus system and changes in brain parenchyma by imaging. Treatment with Unfractionated heparin and LMWH have been reported to be effective in DVST. Our patient improved clinically with LMWH.

\section{Conclusion}

This case is reported for its rare anatomical site and isolated neurological involvement without other systemic complications and successfully treated with Low molecular weight heparin.

\section{References}

1. Masuhr F, Mehraein S, Einhäupl K: Cerebral venous and sinus thrombosis. $\mathrm{J}$ Neurol 2004;251:11-23.

2. Cumurciuc R, Crassard I, Sarov M, Valade D, Bousser MG. Headache as the only neurological sign of cerebral venous thrombosis: a series of 17cases.J Neurol Neurosurg Psychiatry 2005;76:1084-7.

3. Brown MD, Wick TM, Eckman JR: Activation of vascular endothelial cell adhesion molecule expression by sickle blood cells. Pediatr Pathol Mol Med 2001;20:47-72.

4. Westerman MP, Green D, Gilman-Sachs A, Beaman K, Freels S, Boggio L, Allen

S, Zuckerman L, Schlegel R, Williamson
P: Antiphospholipid antibodies, proteins $\mathrm{C}$ and $\mathrm{S}$, and coagulation changes in sickle cell disease. J Lab Clin Med 1999;134:352-362.

5. Brucker AB, Vollert- Rogenhofer $\mathrm{H}$, Wagner $M$, et al. Heparin treatment in acute cerebral sinus venous thrombosis: a retrospective clinical and MR analysis of 42 cases. Cerebrovasc Dis 1998;8(6):331337.

6. Levine SR, Twyman RE, Gilman S. The role of anticoagulation in cavernous sinus thrombosis. Neurology 1988;38(4):517522.

7. Ferro JM, Canhao P, Stam J, Bousser MG, Barinagarrementeria F. Prognosis of cerebral vein and dural sinus thrombosis: results of the International Study on Cerebral Vein and Dural Sinus Thrombosis (ISCVT). Stroke 2004;35(3):664-670. 